\title{
Assessment of sexual violence and associated factors among high school students in Harari Regional State, Harar Town, Eastern Ethiopia
}

\author{
Jote Markos Cafo, ${ }^{1,}$, Agumassie Semahegn Demisie ${ }^{1}$, Balcha Berhanu Abera ${ }^{2}$ \\ ${ }^{1}$ Haramaya University, College of Health and Medical Sciences School of Nursing and Midwifery, Harar, Ethiopia \\ ${ }^{2}$ Addis Ababa University, College of Health Sciences School of Nursing , Addis Ababa, Ethiopia
}

\section{Email address:}

burqaajote@yahoo.com (J. Markos), agucell@yahoo.com (A. Semahegn), mr.hearta@yahoo.com (B. Berhanu)

\section{To cite this article:}

Jote Markos Cafo, Agumassie Semahegn Demisie, Balcha Berhanu Abera. Assessment of Sexual Violence and Associated Factors among High School Students in Harari Regional State, Harar Town, Eastern Ethiopia. Science Research. Vol. 2, No. 5, 2014, pp. 91-97. doi: 10.11648/j.sr.20140205.12

\begin{abstract}
Background: Sexual violence is any sexual act that is perpetrated against someone's willingness including a completed and or attempt nonconsensual, abusive sex act. This study aimed to determine sexual violence and associated factors among high school students in Harar town, Eastern Ethiopia. Methods: Institutional based cross-sectional study was conducted among youth in high school students. Self administered questionnaire was used to collect quantitative data from randomly selected 432 students and four focus group discussions were held with students by using interview guide semi-structured questionnaire to collect qualitative data. Data were entered to SPSS version 16.0 was used to analyze. Descriptive and logistic regression analyses were computed to quantify sexual violence and associated factors. Statistical association was measured 95\% confidence interval and adjusted odd ratio. Results: Sexual violence among in school adolescents were $25 \%$. Students used addictive drugs like alcohol (18\%), chat and shish (7.2\%) as very important contributing factors for sexual violence's. Use of physical force $(15 \%)$, false promise $(43 \%)$ and use of power $(7.2 \%)$ reported contributing factors. Females dressing style, their act, peer pressure, revenge and males emotionality identified as contributing factors for sexual violence. Sexual violence had different consequences like abortion (32.2\%), vaginal discharge (28.6\%), genital trauma (25\%), and unwanted pregnancy (14.2\%). Conclusion: Sexual violence was common problem of in-school adolescents in Harar town. Female students' behavior also contributed for their sexual violence. Sexual and reproductive health issue information should be provided to create awareness about reproductive rights and life skill.
\end{abstract}

Keywords: Sexual, Violence, Factor, Student, Harar, Ethiopia

\section{Introduction}

According to the United Nations Declaration, violence against women includes any act of gender based violence that results in physical, sexual, psychological harm or suffering to women. Any sexual act, attempt to obtain a sexual act, unwanted sexual comments or advances, against a person's sexuality using coercion, by any person regardless of their relationship to the victim, in any setting, including but not limited to home and work [1, 2, 3]. Sexual violence has serious consequences for women's physical, mental, and reproductive health like depression, loss of self-confidence, injuries, unwanted pregnancy and disability up to death [4]. Sexual violence against women is a crucial violation of human right to liberty and freedom from fear, and is now recognized as a priority public health [5]. Sexual coercion exists along a continuum from forcible rape to nonphysical forms of pressure that compel girls and women to engage in sex against their will. It is common among children, adolescents and women both in industrial and developing countries $[6,7]$.

Gender based violence is one dimension of the broader problem of violence in schools. Violence against female students and teachers creates an atmosphere of intimidation and danger in an environment [8]. School adolescents can be victimized at school that may be verbal harassment, physical nature, such as unwanted touching and contact. It can also be more overtly violent, as in cases where girls are sexually assaulted or raped on or near school premises. Studies in 
Ghana, Zimbabwe and Malawi show that violence against girls by older male students and teachers is very common [9]. A study in Japan shows that $52.5 \%$ of high school students are victim of sexual violence as a result of their sexual behavior, attitudes towards sexuality, young in age and lifestyle [10,11]. A robust risk factor for the occurrence of sexual violence is a history of sexual victimization an adolescent were earlier age at menarche and/or first date, number of dating and sexual partners, history of dating violence, and sexually active peer group [12]. Sex exchange for money or pay other cost increase sexual violence Forced sex is more likely to occur later in the dating relationship compared with earlier [13].

The occurrence of sexual victimization by a date or acquaintance is the use of alcohol by the victim, perpetrator. Alcohol use within the dating or social situation may lead to the misinterpretation of friendly nonsexual cues as sexual invitations, diminish coping responses, and limit the ability of a woman toward off a potential attack [14]. Approximately, $78 \%$ of the victims report sexual assault for the first time when they are children or adolescents. Women who report sexual assault were consumed alcohol four or more times a week, ideate suicide, and perceive their health status to be poorer [15]. Among high school students surveyed nationwide in USA, about $8 \%$ reported having been forced to have sex. Females are more likely to report have forced sex than males [16, 17].

Sexual violence can impact health in many ways. Some ways are serious and can lead to long-term health problems like chronic pain, headaches, stomach problems, and sexually transmitted diseases. Rape results in about 32,000 pregnancies each year. Sexual violence can have an emotional impact as well. Sexual violence is also linked to negative health behaviors [18, 19]. Some long-term consequences include: chronic pelvic pain, premenstrual syndrome, gastrointestinal disorders, gynecological and pregnancy complications [20].

Sexual violence has different psychological and social impact on victims, such fear, anxiety, sleep disturbance, nervousness, post-traumatic stress disorder symptoms like depression and intimate partners, less emotional, lower likelihood of marriage [21, 22]. Gender based violence highly prevalent in sub Saharan African countries in Zambia, south Africa, Kenya were 13\%, $7 \%, 16 \%$ respectively reported sexual violence 15-19 years old [23, 24, 25]. But the problem was very high in Ghana, which violence against women and adolescent girls were 49\% [26, 27]. Studies done Debark Town and Dabat High School north-west Ethiopia with two and sixteen female high school students, grade 9-11 showed that almost two third of students are victim for different forms of sexual violence like rape and sexual harassment[28, 29].

Violence against women is recognizing as major public health and human rights concern in Ethiopia. However, the magnitude of sexual violence and associated factors among in-school adolescent is not deeply recognized in Ethiopia. Therefore, determining the magnitude and indentifying predictors' helps for government officials and any concerned bodies to design prevention and controlling strategies to tackle sexual violence. Preventing sexual violence will contribute to the achievement of MDG number 3 that specifically addresses promotion of gender equality and women's empowerment. This study was aimed to determine the contributing factors and consequences of sexual violence among high school and preparatory students in Harar town.

\section{Materials and Methods}

\subsection{Study Area and Study Period}

The study was conducted high schools students in Harari regional state, Harar town in April 2010. Harar town is the center of the Harari people's national regional state. Harar town is a place where Jugal ancient civilization that register by united nation education, science and culture organization (UNESCO) as historical heritage. The town is located 526 kilo meter distance far from Addis Ababa in the eastern part of Ethiopia. It covers $374 \mathrm{~km}^{2}$ in the northwest of the country. Harar has an estimated total population of 209,000 , of whom 107,000 were males and 102,000 were females. There are four public high schools and two private high schools in the town in 2010. Trade is the main source of income of the residents. Khat is the typical plant that cultivated farmers and source of income the rural part of the region and its surroundings. Khat chewing also considered as one of the parts of culture Harari residents.

\subsection{Study Design and Sampling Procedure}

Institution based Cross-sectional study design was employed to assess the prevalence of sexual violence and associated factors among high school students (regular grade $9^{\text {th }}-12^{\text {th }}$ ) in Harar town. The sample size was determined by considering assumptions of the proportion of sexual violence among high school students in Ethiopia was $15 \%$ from the study done in Addis Ababa, desired precision of 5\% and $95 \%$ confidence level. The $10 \%$ none -response rate and design effect were considered that yields the final sample was 432 . Four focus group discussions comprising 8-12 students were conducted from two male and two female focus group discussions on purposively selected in school adolescents. A series of sampling methods were used to arrive actual study subjects. Multi-stage sampling method was used to select high schools in the town. The stratified sampling proportional too size allocation method was used based on their grade $\left(9^{\text {th }}-12^{\text {th }}\right)$. Finally simple random sampling technique was applied to select actual participants by using their alphabetical registration numbers as sampling frame.

\subsection{Data Collection Instruments and Methods}

Quantitative data were collected from participants using self administered questionnaire. The questionnaire was consisted of sociodemographic characteristics of the student and variables that used to measure sexual violence and its consequences. Focus group discussions were conducted to collect qualitative data. Four focus group discussions segregated by sex were conducted using interview guide in 
order to provide more insight in to complex issues of sexual violence. The male focus groups discussion was moderated by well trained male moderator, while the female was moderated female focus group discussions. Moreover, one assistant moderator was assigned for each group to handle tape recording and note- taking activities during each discussion. Semi-structured questionnaire or interview guide was used to conduct focus group discussion, and tape recorder was also used in addition to taking notes during the discussions.

\subsection{Data Analysis and Processing}

The collected data was categorized and coded on a pre drafted coding sheet. The quantitative data was entered into a computer and analyzed using SPSS version 16.0. The tape recorded qualitative data was transcribed under selected themes based on the question guides and was summarized manually. Descriptive statistics were computed to determine prevalence of the sexual violence and socio-demographic characteristics of students. Binary and multiple logistic regression statistical analysis were carried out to examine the relationship between the outcome variables and selected risk factors. Factors for which significant bivariate association observed were retained for subsequent multivariate analyses using multiple logistic regressions. The $95 \%$ level of confidence, adjusted odd ratio and $\mathrm{p}$ value $<0.05$ was used to determine the statistical significance.

\subsection{Ethical Considerations}

Ethical clearance or approval was obtained from school of graduate studies of Addis Ababa University and then by Institutional reviews board of the University. Permission was obtained from schools directors. Informed verbal consent was obtained from each participant. Confidentiality of the information was kept anonymously.

\section{Results}

Four hundred twenty two students were involved with 402 completed questionnaires that were $95.2 \%$ response rate. More than half $(51.5 \%)$ of them were female and 195(48.5\%) were males students. Majority $(89.1 \%)$ of the students were from rural residence. The mean age of student's was 17.1 years old. The predominant religion of the participants were Orthodox (45.3\%) followed by Muslim (44.8\%). Majority of the study participants $(47.8 \%)$ live with their mothers [Table1].

Regarding the sexual history of the participants, $171(42.5 \%)$ of them have boy/girl friend. Seventy seven $(19.2 \%)$ of the study participants ever had sex (58.4\% male; 41.6\%female). The students mean age at first sexual intercourse was 16.5 years old. About $8.2 \%$ of the female students had sexual intercourse with their teachers. Twenty five students had sexual intercourse with their boy/girl friends. Only $2.2 \%$ of the participants had their first sex with their husband/wife. Five students had their first sexual intercourse with unknown individual, student and family members respectively. Majority of the respondents (48\%) motivated to perform sexual intercourse to sustain their love friends. Twenty five percent performed sex to experience pleasure [Table 2].

Table 1. Socio-demography of high school and preparatory students, Harar, Ethiopia 2010.

\begin{tabular}{|c|c|c|}
\hline Variable & Frequency & Percent \\
\hline \multicolumn{3}{|l|}{ Age } \\
\hline Less than 18 & 333 & 82.8 \\
\hline 19-24 & 66 & 16.4 \\
\hline 25 and above & 3 & .7 \\
\hline \multicolumn{3}{|l|}{ Residence } \\
\hline Rural & 358 & 89.1 \\
\hline Urban & 44 & 10.9 \\
\hline \multicolumn{3}{|l|}{ Sex } \\
\hline Male & 195 & 48.5 \\
\hline Female & 207 & 51.5 \\
\hline \multicolumn{3}{|l|}{ educational status } \\
\hline $9^{\text {th }}$ & 322 & 80.1 \\
\hline $10^{\text {th }}$ & 4 & 1.0 \\
\hline $11^{\text {th }}$ & 68 & 16.9 \\
\hline $12^{\text {th }}$ & 8 & 2.0 \\
\hline \multicolumn{3}{|l|}{ Ethnicity } \\
\hline Oromo & 154 & 38.3 \\
\hline Amhara & 31 & 7.7 \\
\hline Harari & 161 & 40.0 \\
\hline Others & 56 & 13.9 \\
\hline \multicolumn{3}{|l|}{ Religion } \\
\hline Muslim & 180 & 44.8 \\
\hline Orthodox & 196 & 48.8 \\
\hline Protestant & 23 & 5.7 \\
\hline Others & 3 & .7 \\
\hline \multicolumn{3}{|l|}{ Respondent's marital status } \\
\hline Married & 23 & 5.7 \\
\hline Not married & 379 & 94.3 \\
\hline \multicolumn{3}{|c|}{ Living condition of respondents } \\
\hline Both parents & 65 & 16.2 \\
\hline Mother only & 192 & 47.8 \\
\hline Father only & 16 & 4.0 \\
\hline Friends & 82 & 20.4 \\
\hline Relatives & 21 & 5.2 \\
\hline Husband/wife & 5 & 1.2 \\
\hline Alone & 21 & 5.2 \\
\hline \multicolumn{3}{|l|}{ Reason of living alone } \\
\hline Parents living out of city & 11 & 52.4 \\
\hline Parents not alive & 6 & 28.5 \\
\hline Parents separated & 3 & 14.3 \\
\hline Others & 1 & 4.8 \\
\hline
\end{tabular}


Table 2. History of sexual relation of the respondents Harar, Eastern Ethiopia, 2010.

\begin{tabular}{lll}
\hline Variable & Frequency & Percentage \\
\hline Current boy/girl friend & 171 & \\
Yes & 231 & 42.5 \\
No & & 57.5 \\
Ever had sex & 77 & \\
Yes & 325 & 19.2 \\
No & & 80.8 \\
Age of first sex & 65 & \\
Less than 18 & 12 & 84.4 \\
Greater than 18 & & 15.6 \\
Age of encounter & 52 & 67.5 \\
Less than 18 & 25 & 32.5 \\
Greater than 18 & & \\
Who is encounter & 9 & 2.2 \\
Husband/wife & 25 & 6.2 \\
Boy/girl friend & 2 & .5 \\
Student & 5 & 1.2 \\
Unknown individual & 33 & 8.2 \\
Teacher & 3 & .7 \\
Family member, specify & & \\
Main motivation for first sex & 8 & 10.4 \\
Got married & 37 & 48 \\
Love affaire & 25 & 32.5 \\
To experience pleasure & 7 & 9.1 \\
Others & & \\
Sex before marriage & 65 & 16.2 \\
Agree & 337 & \\
Disagree & & \\
\hline
\end{tabular}

Twenty eight $(25.9 \%)$ students had ever experienced rape, of which $24(85.7 \%)$ encountered within less than 15 years and four of them were raped between 15-17 years of age. Fifty percent of females students raped by their boyfriends. Twenty five percent of the girls raped by group of individuals that they do not know. The students raped by unknown individual, schoolmates, teacher and family member (not specified) $11 \%, 7.2 \%, 3.4 \%, 3.4 \%$ respectively. Among rape cases, $25 \%$ of the rape were in the school, $21.4 \%$ were raped in the park and $17.8 \%$ raped in their home. The rest, $17.8 \%$, $14.3 \%$, and $3.6 \%$ were raped in the Hotel, perpetrators home and in the car respectively. Most of the girls (53.6\%) were raped in the afternoon. The respondents were also asked to remember contributing factors for their rape. Out of the total respondents, $42.8 \%$ remembered that the perpetrators were used false promises, $17.6 \%$ reported that they have drunk alcohol.

One female discussant strongly agreed for the idea that says alcohol and khat as contributing factors for sexual violence, "....it is very common in this area that boys take girls to khat and hashish houses and make her drunk, and then they will do what they wanted on her and release her..." Other female discussant from different group said "....Even though it is her right for a girl to dress as she likes, majority of the discussants supported that females dressing style especially short dressing disposes her to be violated sexually.....Males cannot control their emotions, females do not have their own self confidence and I believe these two conditions lead for a girl to be a victim of sexual violence..."

One 11 grade girl discussant, "....I know one girl who was rapped due to her own female friend pressure. Her friend said to her she will take her to study group and taken her to chat and hashisha house, there they gave her hashisha and did to her what they wanted" one grade $12^{\text {th }}$ female student...." Physical force used by $14.4 \%$ of the perpetrators, $7.2 \%$ of the raped girls used Hashish or other drugs. The rest $7.2 \%$ and $3.6 \%$ raped by use of authority and during sleep respectively.

The respondents asked if there is any condition for a boy to have sexual intercourse against the girls will and $27.3 \%$ of them responded that it is acceptable if she is wearing closes that reveals her body like short dresses. Twenty three percent of the respondents said it is acceptable if she is his wife, if she is willing to spend the night with him (12.9\%). The remaining $14.4 \%, 6.2 \%, 6.2 \%, 4.8 \%$, and $4.3 \%$ said if she is willing to go to home and hotel, if both were sexually exited, if she is his girlfriend, if she acted in suggestive manner and if they had sex before. Majority of the rape victims (60.7\%) told their problem to their friends and $28.5 \%$ were told to nobody. The rest $3.6 \%, 3.6 \%$, and $3.6 \%$ told to brother, parents and religious leaders respectively. Only one victim has applied to legal body and the perpetrator was released free.

One third (32.2\%) of students experienced abortion, $28.6 \%$ had vaginal discharge, $25 \%$ encountered genital trauma and $14.2 \%$ had unwanted pregnancy. Various psychological problems were reported such as suicidal ideation $(10.8 \%)$, anxiety $(10.7 \%)$, fear $(10.7 \%)$ and depression $(7.1 \%)$. The remaining developed the problem of sexual dysfunction (7.1\%) and $7.1 \%$ of the victims became alcohol or other drugs dependent. Seventy six percent of the students dropped out of schools because of their bad experience [Table 3].

Among the study participants who were victims of sexual violence, majority of them 317 were grade 9-10 and unmarried girls. Regarding their living condition, girls who live with single parent were more vulnerable for violence than others[Table 4].

Table 3. Consequences of sexual violence among high school and preparatory students of Harar Town, Eastern Ethiopia, 2010

\begin{tabular}{lll}
\hline Variable & Frequency & Percent \\
\hline Physical consequence ( outcome) of & & \\
rape (n=28) & 8 & 28.6 \\
Vaginal discharge & 7 & 25 \\
Genital trauma & 4 & 14.2 \\
Pregnancy & 9 & 32.2 \\
Abortion & & \\
Psychological consequences of rape & 2 & 7.1 \\
Self blame & 3 & 10.7 \\
Fear & 3 & 10.7 \\
Anxiety & 2 & 7.1 \\
Depression & 2 & 7.1 \\
Sexual dysfunction & 2 & 7.1 \\
Alcohol or drug dependence & 10 & 35.8 \\
School failure/dropout & 1 & 3.6 \\
Non specific physical complain & 3 & 10.8 \\
Suicidal ideation &
\end{tabular}


Table 4. Factors associated to sexual violence among the study participants in high schools and preparatory schools of Harar Town, April, 2010

\begin{tabular}{|c|c|c|c|c|}
\hline \multirow{2}{*}{ Variable } & \multicolumn{2}{|c|}{ sexual violence } & \multirow{2}{*}{$\operatorname{COR}(95 \% \mathrm{CI})$} & \multirow{2}{*}{$\operatorname{AOR}(95 \% \mathrm{CI})$} \\
\hline & Yes & No & & \\
\hline \multicolumn{5}{|l|}{ Educational status } \\
\hline 9- 10 grade & 317 & 9 & $2.7(1.3-5.7)$ & \multirow{2}{*}{$2.7(1.2-6)$} \\
\hline 11-12grade & 76 & 19 & 1 & \\
\hline \multicolumn{5}{|l|}{$\begin{array}{l}\text { Respondents } \\
\text { marital status }\end{array}$} \\
\hline Married & 3 & 20 & 1 & 1.0 \\
\hline Single & 25 & 354 & $5.5(1.2-25)$ & $2.8(0.5-15)$ \\
\hline \multicolumn{5}{|l|}{ With whom they } \\
\hline \multicolumn{5}{|l|}{ live } \\
\hline Both parents & 5 & 60 & Reference (1) & 1.0 \\
\hline $\begin{array}{l}\text { Live with single } \\
\text { parent }\end{array}$ & 12 & 196 & $2.9(1.12-7.8)$ & $1.7(0.6-5)$ \\
\hline Alone & 3 & 18 & $6.4(1.4-29)$ & $4.7(1-23)$ \\
\hline Others & 5 & 103 & $6.5(2.3-18)$ & $3.9(1.3-12)$ \\
\hline \multicolumn{5}{|l|}{$\begin{array}{l}\text { Current having } \\
\text { boy or girl friend }\end{array}$} \\
\hline Yes & 8 & 163 & $3(1.6-5.3)$ & \multirow{2}{*}{$2.7(1.6-4.8)$} \\
\hline No & 17 & 214 & 1 & \\
\hline
\end{tabular}

\section{Discussion}

This study determined the prevalence of sexual violence against in school adolescents and contributing factors. The findings from this study showed that more than one fourth of students had experienced different forms of sexual violence for the last 12 months period. Four out of every ten student were sexually active. Out of those girls who started sexual initiation, $19.2 \%$ of them performed sexual intercourse of which $84.4 \%$ performed it at age less than 18 years. The study participants encountered various forms of sexual violence. Out of 108 victims, 69 (63.9\%) reported that offensive sexual language or comments and $24(22.3 \%)$ of them said inappropriate touch. Frequency of rape indicated that out of the total sexually active girls, $25.9 \%$ were raped. In relation to this some $35.8 \%$ of the respondents reported that, they knew a girl who was raped. The perpetrators while raping the victims used different mechanisms. The major techniques include giving false promises $(42.8 \%),(17.6 \%)$ making the victims drunk and $14.4 \%$ of perpetrators used physical force. Seven percent of the perpetrators used shisha before raping the girls. Majority of the study participants were from rural area, so they may be easily cheated by promising words. As we can see from socio-demography, the perpetrators were older than the victims so they can use physical force. Chemicals like alcohol and shisha are easily accessible in the study area that the perpetrators used these chemicals to victimize the girls. Studies from overseas revealed similar findings and some studies done in Ethiopia underlined the use of alcohol and other substances as contributing factors for sexual violence which supports my findings [14].

This study revealed different sexual violence consequence reported by victims. Almost one third of sexual violence victim students had history of abortion, one fifth of victim's experienced vaginal discharge, one fourth had genital trauma as a result of forced sexual intercourse and approximately one out of every seven victims of sexual violence had unwanted pregnancy. This finding is quite higher than a study done in New York sexual violence victim reported different consequence $[15,16]$. This might be due to sexual violence victims keep silent with reporting to any legal bodies as supported from discussants. However, this finding is almost similar with a study conducted in Addis Ababa and Debark town of north Gondar zone [17, 18, 19].

This finding indicated that almost one in every ten student use addictive substance among victim of sexual violence and also had experienced suicidal ideation, anxiety, depression, sexual dysfunction and self blame. This finding is lower compared to the study done in Jimma Zone showed that anxiety $(23.6 \%)$ and depression (10.3\%). n showed $53 \%$ anxiety, $41 \%$ self blame which is also higher compared to our finding. Majority of the victims of rape $(35.8 \%)$ dropped out of the school, higher when compared to the study done in Jimma Zone among school girls which is $26 \%$ may be because majority of our study participants were from rural area $[20,21,22,23]$. From the total 107 male participants involved in the study, $2.8 \%$ were raped in their life time which is less compared to the result of a study done in USA that revealed $4 \%[24,25]$. From focus group discussion the male group discussants mentioned that rape of male is uncommon but recently they had information as males of less age are violated by males of older ages.

A low grade (9-10) is strongly associated with sexual violence students in lower grades are almost three times at risk for sexual violence. Similarly, participants who are single were five times at risk for sexual violence than respondents who were married. This might be because students who are single get chance of meeting different males that increases their chance of being violated. Participants who were living with their single parents and who were living alone were more prone than students who were living with both parents. Respondents who were with boy/girl friend were three times at risk for sexual violence [26, 27]. Student behavior like dressing, different acts, consider as revenge of their ex-partner, alcohol, khat and peer pressure were identified as contributing factor from quantitative study and supported by qualitative study. This finding is consistent with a studies done Debark and in Jimma town which revealed $8.8 \%$ and $26.9 \%$ of students had experienced sexual violence respectively [28, 29].

\subsection{Implication of this the Findings}

Ethiopia is a state party to many international and regional human rights. Violence against women is recognizing as major public health and human rights concern in Ethiopia. Therefore, determining the magnitude and indentifying predictors' helps for government officials and any concerned bodies to design prevention and controlling strategies to tackle sexual violence. Preventing sexual violence will contribute to the achievement of MDG number 3 that specifically addresses promotion of gender equality and women's empowerment. In addition, assuring gender equality is recognized as key in achieving all eight goals. Information obtained here can be used for planning 
of intervention programs in different part of the country.

\subsection{Strengths and Limitations of the Study}

It has quantitative and qualitative methods considered as strength of this study. The participants might have social desirability biased and recall bias and also inferring cause and effect relationships might be difficult.

\section{Conclusion}

This study revealed that more than one fourth of female students were victim of various forms of sexual violence. Approximately two third students reported offensive sexual language and others inappropriate touch, attempted rape and unwelcomed kissing. Almost two out of every ten student were use of addictive drugs like alcohol, chat and hashish. Females dressing style, their act, peer pressure, revenge and males emotionality were identified as contributing factors for sexual violence. At least one out of every five students had experience consequences like abortion, vaginal discharge, genital trauma, unwanted pregnancy, suicidal ideation, anxiety, fear and depression. Education about sexuality and reproductive health issues should given starting from elementary because students at lower grade were at increased risk for this problem by incorporate in their curriculum. Educating had girls about their reproductive rights and improving their life skill or assertiveness.

\section{Competing Interest}

All authors declared that we have no any competing interest

\section{Authors' Contribution}

JM had made substantial contribution to conception, design or acquisition of data, analysis and interpretation of findings. AS and BB had revised the paper critically for important intellectual content. All authors read and approved the final manuscript.

\section{Acknowledgment}

We would like to thank to Addis Ababa University for financial support. we would like to express our thanks to the school principals who permitted and facilitated the conduct of this study. Finally we thank all participants of this study.

\section{References}

[1] Heise L, Ellsberg, M, Goheemoeller, M. Ending violence against women, Population Report Series, 1999, Vol. 1 pp.11.

[2] Basile K, Saltzman L. Sexual violence surveillance. Centers for Disease Control and Prevention Atlanta: National Center for Injury Prevention and Control; 2002.

[3] WHO. Understanding Sexual Violence Fact Sheet. World Health Organization, Geneva, 2008.
http://www.who.int/mediacentre/factsheetHtml (accessed 5 Dec. 2009).

[4] World Health Organization. Violence against Women: A Priority Health Issue, World Health Organization, Geneva, Switzerland, 1997.

[5] Kapur, P. Girl child abuse: violation of her human rights, Social Change, 1995, 25(2): 3-18.

[6] United Nations Development Fund for Women. A world free of violence against women, United Nations Inter-Agency Global Video Conference, United Nations Development Fund for Women, New York, 1998.

[7] McCauley, A.P, Salter, C. Meeting the needs of young adults, Population Report, 1995, 5(41):1-11.

[8] Silverman, J. Raj, A, Mucci A, Hathaway E. Dating violence against adolescent girls and associated substance use, unhealthy weight control, sexual risk behavior, pregnancy, and suicidal. Journal of the American Medical Association, 2001; 286: $572-579$.

[9] Victims of crime in the developing world. Rome, United Nations Interregional Crime and Justice Research Institute, 1998.

[10] Mikiko N, Yasushi N, Sueko K, Kayoko O. Experience of sexual violence among sexually experienced Japanese teenage girls and influencing factors. Reproductive Medicine and Biology , 2008; 7(4). 1-9

[11] Abbey A, Ross L, McDuffie D, McAuslan P. Alcohol and dating risk factors for sexual assault among college women. Psychol Women Q. 1996; 6 (20):147-169.

[12] Vicary J, Klingaman L, Harkness W. Risk factors associated with date rape and sexual assault of adolescent girls. J Adolesc. $1995 ; 18: 289-306$.

[13] Ware S, Dziuba-Leatherman J, Stapleton J, Yodanis L. Acquaintance and Date Rape: An Annotated Bibliography. Westport, Conn: Greenwood Press; 1994.

[14] Abbey A. Acquaintance rape and alcohol consumption on college campuses: how are they linked? J Am Coll Health. 1991; 39:165-169.

[15] Saba W. Masho, Rebecca K. Sexual assault in Virginia: A population-based study. Women's Health Issues. 2005; 15(4): 157-166.

[16] Holmes M, Resnick H, Kilpatrick D, Best C. Rape-related pregnancy: estimates and descriptive characteristics from a national sample of women. American Journal of Obstetrics and Gynaecology. 1996; 175:320-324.

[17] Centers for Disease Control and Prevention. Youth risk behaviour surveillance United States, 2006; 55(5):1-112. www.cdc.gov/mmwr/PDF/SS/SS5505.pdf (accessed Nov.21/2009)

[18] Eva W, Ewa M. Perceptions of sexual harassment in Swedish high schools: experiences and school-environment problems. European Journal of Public Health. 15(1).

[19] Douglas, K. A. et al. "Results From the 1995 National College Health Risk Behavior Survey." Journal of American College Health 46 (1997): 55-66 
[20] Jewkes R, Sen P, Garcia-Moreno C, Krug E, Dahlberg L, Mercy J. World Report on Violence and Health. Geneva, Switzerland: WHO, 2002, pp. 213-239.

[21] Felitti V, Anda R, Nordenberg D, Williamson D, Spitz A, Edwards V. Relationship of childhood abuse and household dysfunction to many of the leading causes of death in adults: the Adverse Childhood Experiences study. American Journal of Preventive Medicine. 1998; 14:245-258.

[22] Clements P, Speck P, Crane P, Faulkner M. Issues and dynamics of sexually assaulted adolescents and their families. International Journal of Mental Health Nursing 2004; 13 (4):267-274.

[23] Mujgan A. Sexual abuse among female high school students in Istanbul, Turkey. Child Abuse \& Neglect. 2006; 30 (3): 247-255.

[24] Centeral statistics agency [Zambia]. Zambia Demographic and Health Survey. 2001. http://www.measuredhs.com/pubs/pdf/FR211/FR211\%5Brevis
ed-05-12-2009\%5D.pdf (Accessed on 21 Dec/2009):

[25] Central statistics agency [Kenya]. Kenya Demographic and Health Survey.2003. www.knbs.go.ke/../KenyaDemographicandHealthSurvey2003 _Preliminary_Report.pdf

[26] World Health Organization (WHO), Multi-country Study on Women's Health and Domestic Violence against Women: summary report of initial results on prevalence, health outcomes and women's responses, Geneva: WHO, 2005.

[27] Appiah C and Cusack K, Violence against Women and Children in Ghana: Report of a National Study on Violence 1999, Gender Studies and Human Rights Documentation Centre: Accra, Ghana.

[28] Worku A. Sexual violence among female high school students in Debark, North West Ethiopia. East Afr Med J. 2002; 79(2):96-97.

[29] Mekkonnen G, Asresash D. Sexual violence against schoolgirls in Jimma Zone. Ethiop. J. Educ. \& Sc. 2007; 2 (2). 